\title{
Исследование модифицированной структуры квантового каскадного лазера
}

\author{
() В.В. Мамутин, Н.А. Малеев, А.П. Васильев, Н.Д. Ильинская, Ю.М. Задиранов, \\ А.А. Усикова, М.А. Яговкина, Ю.М. Шерняков, В.М. Устинов
}

Физико-технический иститут им. А.Ф. Иоффе Российской академии наук, 194021 Санкт-Петербург, Россия

E-mail: mamutin@mail.ru

(Получена 27 апреля 2017 г. Принята к печати 3 мая 2017 г.)

Исследован процесс получения модифицированной структуры для квантовых каскадных лазеров, включающий в себя выращивание с помощью молекулярно-пучковой эпитаксии, плазменное травление, фотолитографию с применением жидкостного травления и создание специальных контактов для уменьшения потерь в волноводе. Использование специального типа структуры позволяет и без постростового заращивания высокоомным материалом достичь параметров, удовлетворяющих требованиям к гетероструктурам высококачественных квантовых каскадных лазеров при максимальном упрощении всего процесса изготовления.

DOI: $10.21883 /$ FTP.2018.01.45332.8630

\section{1. Введение}

Работа квантовых каскадных лазеров (ККЛ) основана на внутризонных оптических переходах в отличие от работы обычных полупроводниковых лазеров с межзонными переходами и рекомбинацией носителей, и длина волны излучения в них задается не материалом, а зонной структурой сверхрешетки активной области. Длина волны может выбираться в широких пределах в зависимости от применения, одно из которых - использование атмосферных окон прозрачности среднего инфракрасного (ИК) диапазона: 3-5 и 8-13 мкм для высокоскоростных систем связи, в том числе со спутниками, когда влияние поглощения и турбулентности атмосферы существенно уменьшено по сравнению с видимым и ближним ИК диапазонами. В лазерах для диапазона длин волн $\lesssim 5$ мкм co слоями InGaAs/AlInAs в основном из-за коэффициента преломления, технологичности и подходящего теплоотвода используются структуры, выращенные на подложках InP [1-8].

Критическим моментом в получении ККЛ, кроме роста активной области из сверхрешеток, оказалась постростовая обработка (processing) - изготовление мезаполосков, контактов и теплоотводов после выращивания лазерной структуры [3]. Для достижения улучшенных характеристик ККЛ (снижения порогов и увеличения дифференциальной эффективности) казалось важным использование заращивающего полосковую структуру материала с улучшенным теплоотводом и повышенным сопротивлением. Таким материалом был технологически совместимый со слоями InGaAs/AlInAs высокоомный фосфид индия [3]. Заращивание позволяло одновременно улучшать как теплоотвод от структуры, так и электрическую изоляцию стенок полоска [4].

Нами предварительно было показано, что после роста структуры в установке молекулярно-пучковой эпитаксии (МПЭ) при использовании дополнительной технологии металлоорганической газофазной эпитаксии (МОГФЭ) возможно качественное бездефектное заращивание лазерной структуры ККЛ высокоомным фосфидом индия (InP) без специальной обработки после переноса из установки МПЭ и контакта с атмосферой [5]. Однако сам метод требовал введения в общую схему дополнительной установки и технологии МОГФЭ, что, конечно, усложняло и удлиняло процесс. Кроме того, получение высокоомного материала само по себе нетривиальная задача. Из-за сильного поглощения и, как следствие, разогрева „обычной“ структуры ККЛ со сплошными контактами требовался усиленный теплоотвод, вплоть до использования алмаза, а также InP и особо толстых ( 5 мкм) золотых контактов [3,4]. В рассматриваемой здесь структуре за счет использования незакрытой поверхности полоска (границы воздух-полупроводник с большим коэффициентом преломления) и устранения поглощения в металле таких усложнений не требуется. Подобная концепция, условно названная „,regrowth-free“, и включающая только один процесс роста в установке МПЭ без последующего заращивания фосфидом индия, ранее давала хорошие результаты со стабильной одномодовой генерацией без перегрева в течение 2500 ч при комнатной температуре [6].

В данной статье сообщается о получении модифицированной структуры ККЛ с несплошными контактами (с открытой поверхностью), рассчитанной на длину волны $\sim 5$ мкм, на основе AlInAs/GaInAs напряженнокомпенсированных (strain-compensated) сверхрешеток с 4-ямной схемой активной области, выращенной МПЭ на подложках InP. В работе проводилось исследование роста, постростовой обработки и характеристик лазерной структуры, выращенной МПЭ с активной областью по аналогии с [7], с целью отработки на имеющемся в ФТИ им. А.Ф. Иоффе оборудовании всех необходимых операций для получения высококачественных приборов (ККЛ).

На сегодня квантово-каскадные лазеры, работающие в диапазоне длин волн 3-5 мкм, выращенные на под- 
ложках фосфида индия, представляют собой в основном полосковую структуру шириной от 5 до 50 мкм, протравленную до подложки InP, с диэлектрической изоляцией на боковых стенках и сплошным омическим контактом на лицевой и тыльной сторонах структуры [3,4,8].

В нашем случае структура после процессинга представляла собой полосок (ridge waveguide) с почти пол-

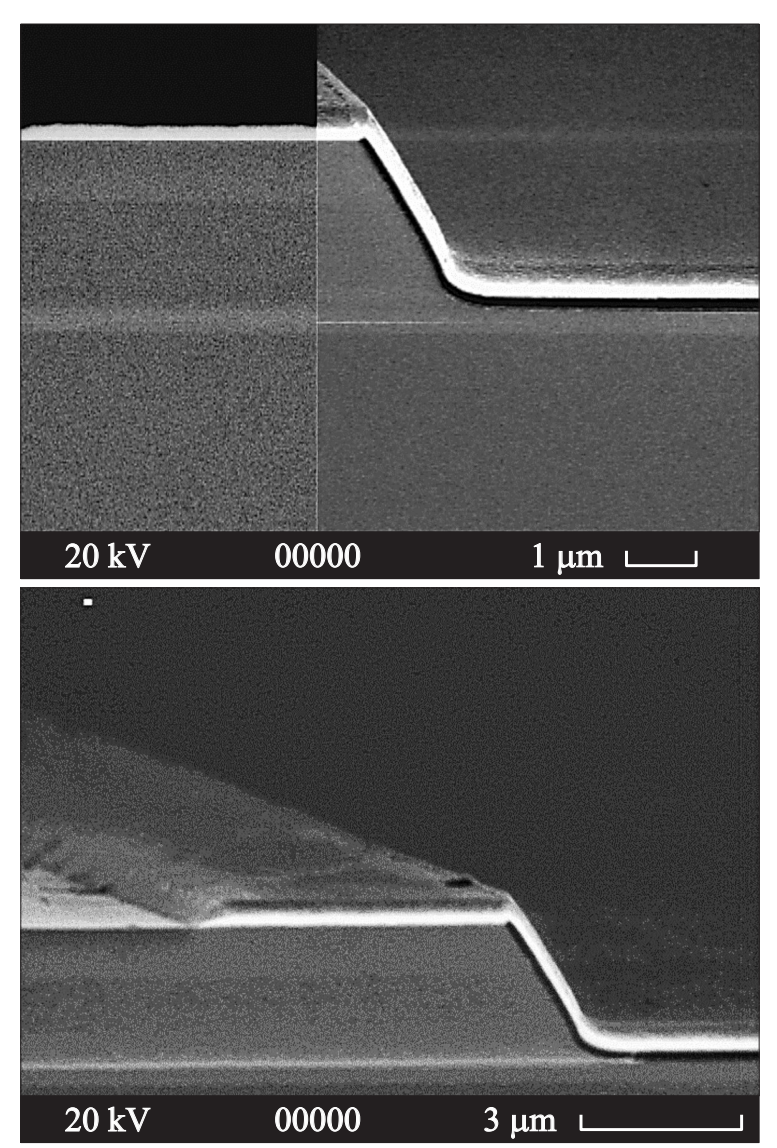

Рис. 1. Вид в электронном микроскопе скола гетероструктуры ККЛ после плазменного травления и нанесения диэлектрика с металлом.

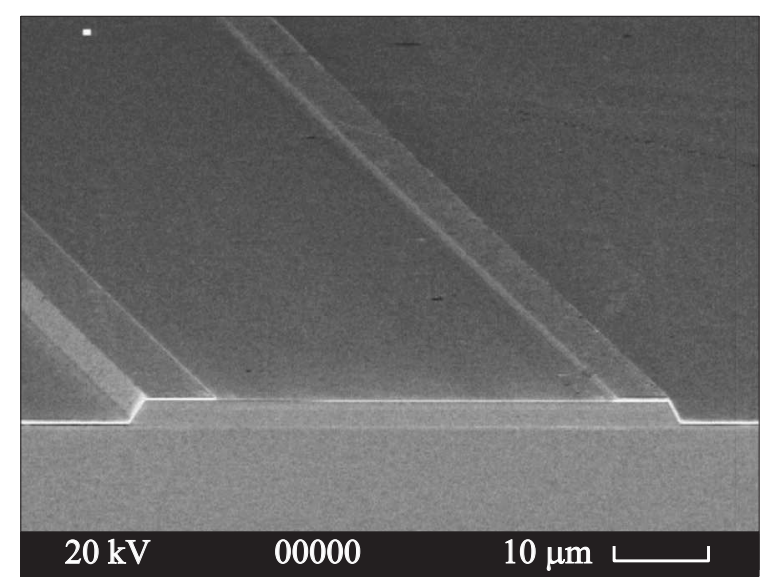

Рис. 2. Общий вид скола ККЛ в электронном микроскопе в уменьшенном масштабе. ностью открытой верхней поверхностью с контактами по краям полоска (рис. 1,2).

Такая конструкция не только значительно упрощает, но и удешевляет весь процесс изготовления по сравнению с другими конструкциями в силу меньшего расхода материалов и сокращения времени в процессе МПЭ, так как исключен рост толстых эмиттеров и исключены трудности получения высокоомного материала (InP) с помощью отдельной технологии (МОГФЭ) [5]. Вся последовательность технологических операций является предварительной для создания лазера с распределенной обратной связью с выводом излучения через дифракционную решетку, нанесенную на поверхность полоска.

\section{2. Эксперимент}

\section{1. Выращивание гетероструктур}

Лазерные гетероструктуры были выращены молекулярно-пучковой эпитаксией на установке RIBER-21 Compact 21TM. Ростовые температуры активных областей лазерных структур составляли $500^{\circ} \mathrm{C}$, и при росте использовались условия слабой стабилизации поверхности мышьяком. Лазерная структура была разработана с напряженно-компенсированной (strain-compensated) активной областью аналогично [7] и наносилась на подложку из $n$-InP : Sn, легированного до $2 \cdot 10^{17} \mathrm{~cm}^{-3}$. Активные области гетероструктур $\mathrm{GaIn}_{x} \mathrm{As} / \mathrm{AlIn}_{y}$ As выращивались в напряженно-компенсированном варианте для увеличения разрыва зон на гетерограницах, чтобы подавить потери свободных носителей в континуум. Напряженно-сжатые ямные области с содержанием индия $x=0.60$ и напряженно-растянутые барьеры с содержанием индия $y=0.44$ приводили к общему напряжению в структурах ниже $10^{-3}$. Активная область квантового каскадного лазера состояла из 30 периодов. Каждый период содержал собственно активную излучающую зону из 4 квантовых ям и инжекторную область из напряженно-компенсированной сверхрешетки. Один период содержал последовательность из 20 чередующихся слоев AlInAs/GaInAs (в нм): 4.2/ $\underline{1.3} / 1.4 / \underline{5.0} / 1.4 / \underline{4.4} / 1.5 / \underline{3.9} / 2.4 / \underline{2.9} / 1.9 /$ $\underline{2.6} / 2.0 / \underline{\mathbf{2} .3} / \mathbf{2 . 1} / \underline{\mathbf{2} .2} / \mathbf{2 . 3 / 2 . 1} / 3.0 / \underline{2.1}$ с ямными слоями GaInAs (подчеркнуты) и выделенными жирным легированными слоями, которые были легированы кремнием на уровне $n=4 \cdot 10^{17} \mathrm{~cm}^{-3}$. Вся структура (последовательность от подложки по направлению роста) состояла из следующих слоев (в скобках приведен уровень их легирования): волноводный слой $\mathrm{Ga}_{0.53} \mathrm{In}_{0.47} \mathrm{As}$ $\left(6 \cdot 10^{16} \mathrm{~cm}^{-3}\right), 340 \mathrm{нм}$, активная зона $1530 \mathrm{Hм} \mathrm{(30} \mathrm{пе-}$ риодов), волноводный слой $\mathrm{Ga}_{0.53} \mathrm{In}_{0.47} \mathrm{As}\left(6 \cdot 10^{16} \mathrm{~cm}^{-3}\right)$, 500 нм, верхний „подконтактный“ сильно легированный слой $\mathrm{Ga}_{0.53} \operatorname{In}_{0.47} \mathrm{As}\left(2 \cdot 10^{18} \mathrm{~cm}^{-3}\right), 400$ нм.

При выборе количества периодов активной области необходимо было учитывать зависимость пороговой 
плотности тока от потерь, усиления и фактора ограничения:

$$
J_{\text {th }}\left(N_{p}\right)=\left(\alpha_{m}+\alpha_{w}\right) / g \Gamma\left(N_{p}\right),
$$

где $J_{\text {th }}\left(N_{p}\right)$ - пороговая плотность тока, $\alpha_{m}$ - потери на отражение. $\alpha_{m}=(1 / L) \ln R$, где $L-$ длина резонатора, $R$ - коэффициент отражения на зеркалах, $\alpha_{w}-$ волноводные потери, $g$ - коэффициент усиления, $\Gamma\left(N_{p}\right)-$ коэффициент оптического ограничения, $N_{p}-$ число периодов активной области. Оказалось, что лазеры c $N_{p}<6$ не дают генерации при комнатной температуре, при увеличении числа периодов с 12 до 75 пороговая плотность тока при $300 \mathrm{~K}$ уменьшается соответственно с 16 до 8 кА/ $\mathrm{cm}^{2}$, а теоретические предсказания хорошо согласуются с экспериментом и дают $J_{\text {th }} \leq 10 \kappa \mathrm{A} / \mathrm{cm}^{2}$ при числе периодов $>20$ [8]. Кроме того, пороговая плотность тока становится независимой от температуры и числа периодов для $N_{p} \geq 20$ с характеристической температурой $T_{0} \geq 100 \mathrm{~K}$. Квантовые каскадные лазеры ведут себя с температурой, как и обычные полупроводниковые лазеры, с пороговой плотностью тока

$$
J_{\text {th }}(T)=J_{0} \exp \left(T / T_{0}\right),
$$

но со значением $T_{0}$ между 100 и $300 \mathrm{~K}$, что является очень большим значением для других полупроводниковых лазеров (обычное значение $T_{0}<100 \mathrm{~K}$ ).

Кроме того, дифференциальная квантовая эффективность становится $>1$ для $N_{p} \geq 12$, а рабочее напряжение при этом не становится „слишком“ большим (3-10 В для 10-40 периодов) [8]. Таким образом, оптимальное количество периодов лежит в пределах 20-40 для удовлетворения всех предъявляемых требований.

Технические трудности для роста общего количества слоев в периодах $(\sim 600)$ определяются возможностями установки и не представляют неразрешимой задачи для нормальной установки МПЭ. Однако с точки зрения времени, расхода материалов и износа установки желательно уменьшать количество слоев, и мы приходим к минимально необходимому количеству периодов $\sim 30$. Это количество и было выбрано в наших структурах.

К тому же использование большего количества периодов, как доказано экспериментально в работе [9], было излишним. Вырастившие 60 периодов авторы пишут, что это „не приводит к желаемому увеличению квантовой эффективности и оптической мощности, а лишь приводит к увеличению электрического напряжения и дополнительному разогреву лазера. Периферийные каскады фактически не работают“. Это было известно и из работы классиков ККЛ [8] еще в 2001 г.

\section{2. Постростовая обработка (processing)}

Процесс постростовой обработки (processing) состоял из последовательных технологических этапов, приводящих к получению мезаполосковой гребневой структуры (ridge waveguide), частично покрытой металлом (по краям полоска). Полоски вытравливались до нижнего волноводного слоя, покрывались диэлектриком на боковых стенках, подложка утончалась, наносились верхний и нижний слои металла, удалялась часть металла верхнего контакта с середины полоска, и раскалывались на чипы длиной 1, 2 и 3 мм (как в обычном полупроводниковом лазере, без внесения дополнительных усложняющих операций). Единственное отличие состояло в том, что верхний контакт был не сплошным и не закрывал всю верхнюю поверхность полоска.

Изготовление прибора начиналось с формирования мезаполосковой структуры шириной 55 мкм. Методом ионно-лучевого травления через маску фоторезиста вытравливалась меза на глубину, соответствующую остановке процесса травления на нижнем волноводном слое $\mathrm{Ga}_{0.53} \mathrm{In}_{0.47} \mathrm{As}$ толщиной $340 \mathrm{Hм}$, что хорошо видно на рис. 1. Для получения диэлектрического покрытия мы использовали пленки $\mathrm{TiO}_{2} / \mathrm{SiO}_{2}$. Слои такого диэлектрика, как показывает наш опыт, являются более плотными по сравнению со слоями двуокиси кремния, поэтому необходимая толщина защитного покрытия может быть выбрана меньше $\left(\leq 0.2\right.$ мкм), чем в случае слоев $\mathrm{SiO}_{2}$, что обеспечивает лучший теплоотвод.

При использовании ионно-лучевого травления на боковой поверхности мезы в результате бомбардировки полупроводниковой структуры атомами Ar остается нарушенный слой, который может приводить к появлению утечек. Для удаления данного слоя был использован травитель на основе сильно разбавленного раствора $\mathrm{HBr}$ и $\mathrm{H}_{2} \mathrm{O}_{2}$ в воде с очень низкой скоростью травления $V=0.05$ мкм/мин, обеспечивающий одинаковую скорость травления различных по составу слоев структуры и, как следствие, гладкую поверхность боковой стенки полоска. Снятие нарушенного слоя с лазерной структуры проводилось непосредственно после сухого травления, глубина обработки составила $\sim 0.1$ мкм.

После этого проводили пассивацию боковой стенки мезы диэлектриком. На образец методом магнетронного распыления на установке BAS450 Balzers наносили диэлектрическое покрытие $\mathrm{TiO}_{2} / \mathrm{SiO}_{2}$. Были подобраны следующие режимы: температура процесса $200^{\circ} \mathrm{C}$, оптимизированая толщина $\sim 180$ нм. Последующее удаление маски фоторезиста в органических растворителях приводит к освобождению контактного слоя наверху полоска, при этом боковая стенка мезы закрыта диэлектриком. Использование одной маски фоторезиста для травления мезы и пассивации ее боковой стенки позволяет сократить количество фотолитографиий.

Далее проводилось утончение подложки до $\sim 170$ мкм. Сплошной обратный $n$-контакт $\mathrm{AuGe}-\mathrm{Ni}-\mathrm{Au}$ суммарной толщиной 300 нм напылялся на установке ВУП-5М методом термического испарения в вакууме. Для получения омических характеристик контакта был проведен RTA (rapid thermal annealing) - отжиг в атмосфере $\mathrm{H}_{2}$ при температуре $370^{\circ} \mathrm{C}$, длительностью $t=30$ c. Для лучшего теплоотвода и уменьшения 
сопротивления было проведено усиление контакта дополнительным напылением $200 \mathrm{Hм} \mathrm{Au}, \mathrm{B}$ качестве адгезионного слоя использовался Сr толщиной $\sim 20$ нм.

Верхний контакт был не сплошным, а имел следующую конфигурацию: металл покрывает боковую стенку полоска поверх диэлектрика и образует на поверхности контактного слоя на краях две полосы шириной 6-7 мкм (рис. 2). Это позволяет обеспечить хорошие контактные характеристики и оставляет широкую свободную от металла зону или „окно“ для исключения поглощения лазерного излучения в металле $(\sim 75 \%$ поверхности). В дальнейшем такая конструкция позволит изготовить на свободной поверхности дифракционную решетку для вывода одномодового излучения, т.е. создать базу для изготовления лазера с распределенной обратной связью (DFB - distributed feedback laser).

Для формирования такой топологии лицевого (верхнего) контакта применялся метод „взрывной“ фотолитографии. Часть полоска, где требовалось создать „окно“, закрывалась маской фоторезиста, проводилось напыление металла, затем резист удалялся в органических растворителях, а вместе с тем вскрывалось „окно“. Слой напыляемого металла должен быть достаточно толстым для проведения последующей качественной распайки чипов, поэтому для облегчения „взрыва“ использовалась двухслойная маска со специальным резистом LOR (lift off resist). В качестве материала к контактам была выбрана система: адгезионный слой Сr 20 нм и толстый слой 450 нм Аu. Контакт не вжигался.

\section{3. Основная часть}

\section{1. Исследование структуры квантового каскадного лазера методом рентгеновской дифрактометрии}

Рентгенодифракционные исследования проводились на рентгеновском дифрактометре D8 Discover, Bruker, Германия. Источником излучения мощностью 6 кВт являлась трубка с вращающимся медным анодом (длина волны $\lambda=0.15406$ нм). Дифракционные кривые были получены в трехкристальной геометрии с использованием бартелевского четырехкратного проточного кристалла-монохроматора и трехкратного проточного кристалла-анализатора $\mathrm{Ge}(220)$. Полуширина первичного пучка не превышала $12^{\prime \prime}$. Исследовалась вся пластина диаметром 5 см после роста, до раскола и проведения процесса фотолитографии.

Дифракционные кривые получены $2 \theta / \theta$-сканированием в области угла отражения от плоскости (004) InP. Полученные дифрактограммы приведены на рис. 3. Развитая интерференционная картина наблюдается в широком угловом диапазоне, $>10^{\circ}$ по шкале $2 \theta$, что указывает на планарность и непрерывность интерфейсов, образующих периодическую структуру. Максимумы толщинных осцилляций имеют малую полуширину без расщеплений, что соответствует постоянству состава и

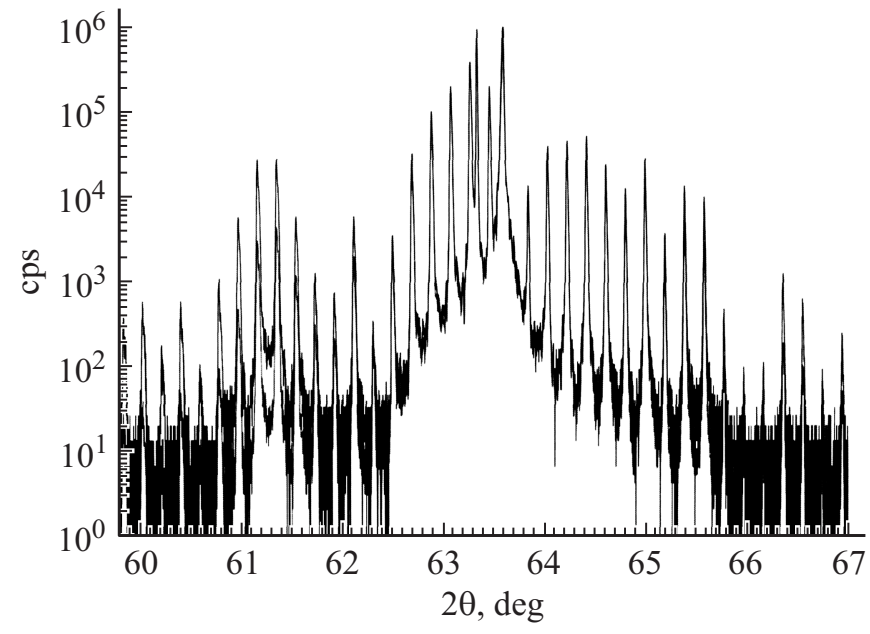

Рис. 3. Картина дифракции структуры ККЛ в центре пластины и на крае в диапазоне $60-67^{\circ}\left(\mathrm{Cu} K_{\alpha}\right.$-излучение, длина волны $\lambda=0.154 \mathrm{HM})$

толщин периодов „сверхрешетки“. В целом наблюдаемая дифракционная картина показывает высокое структурное совершенство ККЛ. Уход от расчетных величин составлял на 30 периодов $\sim 0.4 \%$ по толщине, что соответствует $\sim 1.6$ монослоя (ML) (рис. 3). Естественная точность (по природе МПЭ) не может превышать 1 монослоя.

\section{2. Исследование электрических характеристик структуры}

Для предварительной оценки электрических характеристик снимались вольт-амперные характеристики $(\mathrm{BAX})$ без напайки образцов на теплоотвод на прижимном зонде. Вольт-амперная характеристика изме-

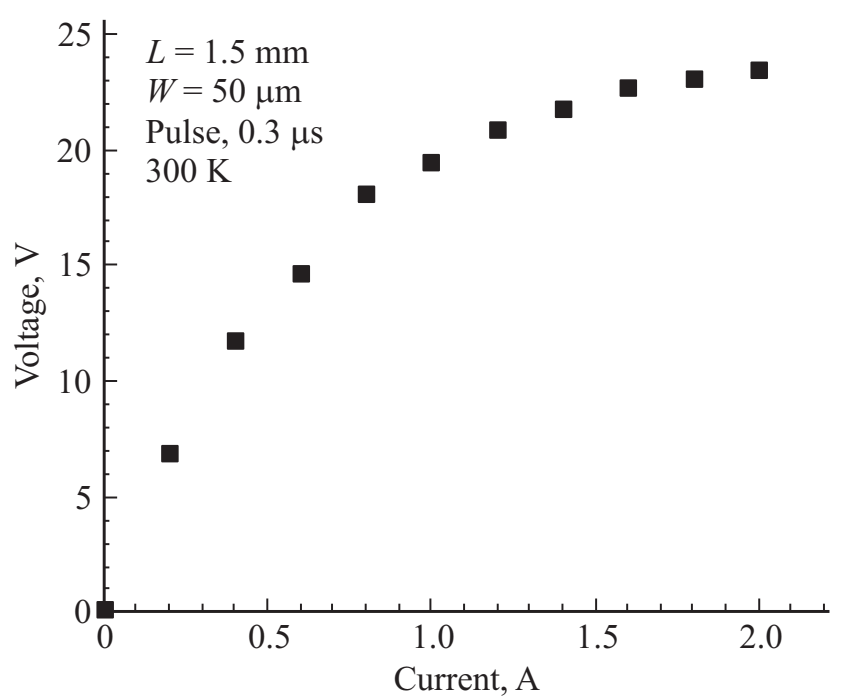

Рис. 4. Вольт-амперная характеристика исследуемой структуры ККЛ. Параметры указаны. 
рялась при комнатной температуре в импульсном режиме (длительность импульсов 100 нс, частота следования $\sim 5$ кГц). Длина полоска была $L=1.5$ мм, ширина $W=50$ мкм, температура $300 \mathrm{~K}$. (рис. 4). Выдерживаемые структурой напряжения представляются достаточными для создания туннелирования и выхода в режим генерации (типичные напряжения, приводимые в иностранной литературе, составляли 10-15 В). С другой стороны, они близки к напряжениям в структурах, выращенных в нашей стране [9]. Более подробное исследование характеристик структуры будет опубликовано в отдельной работе.

\section{4. Заключение}

В статье показано исследование модифицированной структуры квантового каскадного лазера, выращенной МПЭ, без толстых эмиттеров, с оптимальным числом каскадов, сформированной с помощью фотолитографии, плазменного и жидкостного химического травления. Показана возможность достижения на имеющемся оборудовании всех необходимых для ККЛ параметров с упрощением процесса по сравнению со „стандартными“, известными ранее. Полученные структуры позволят в дальнейшем перейти к изготовлению лазера с распределенной обратной связью и отвечают требованиям, предъявляемым к гетероструктурам высококачественных ККЛ.

Рентгенодифракционные исследования параметров ККЛ выполнялись с использованием оборудования федерального ЦКП „Материаловедение и диагностика в передовых технологиях“ ФТИ им. А.Ф. Иоффе РАН, Санкт-Петербург.

Авторы выражают благодарности С.И. Трошкову за исследование образцов на электронном микроскопе.

\section{Список литературы}

[1] В.В. Мамутин, В.М. Устинов, J. Boetthcher, Н. Kuenzel. ФТП, 44, 995 (2010).

[2] V.V. Mamutin, V.M. Ustinov, N.D. Ilyinskaya, M.V. Baydakova, B.Y. Ber, D.Y. Kasantsev. J. Phys.: Conf. Ser., 291, \#012008 (2011).

[3] A. Tsekoun, R. Go, M. Pushkarsky, M. Razeghi, C.K.N. Patel. PNAS (Proc. of Nat. Acad. of Sci. of USA), 103, 4831 (2006).

[4] M. Razeghi, S. Slivken, Y. Bai, B. Gokden, S.R. Darvish. New J. Phys., 11, 125017 (2009).

[5] В.В. Мамутин, Н.Д. Ильинская, Б.В. Пушный, Р.В. Левин, Д.А. Бедарев. ФТП, 48, 1132 (2014).

[6] R.M. Briggs, C. Frez, C.F. Borgentum, S. Forouhar. Appl. Phys. Lett., 105, 141117 (2014).

[7] D. Hofstetter, M. Beck, T. Aellen, J. Faist. Appl. Phys. Lett., 78, 396 (2001)

[8] C. Gmachl, F. Capasso, D.L. Sivco, A.Y. Cho. Rep. Prog. Phys., 64, 1533 (2001).
[9] А.В. Бабичев, Н.А. Пихтин, И.С. Тарасов, Е.В. Никитина, А.Н. Софронов, Д.А. Фирсов, Л.Е. Воробьев, И.И. Новиков, Л.Я. Карачинский, А.Ю. Егоров. ФТП, 50, 1320 (2016).

Редактор Л.В. Шаронова

\section{Investigation of modified structure for quantum cascade lasers}

V.V. Mamutin, N.A. Maleev, A.P. Vasilyev,

N.D. Ilyinskaya, Yu.M. Zadiranov, A.A Usikova, M.A. Yagovkina, Yu.M. Shernyakov, V.M. Ustinov

loffe Institute, 194021 St. Petersburg, Russia

Abstract We have demonstrated MBE growth and postgrowth processing for fabrication of modified quantum cascade laser structure with special contacts to prevent large absorption losses in the waveguide. Using this modified design of structure and regrowth-free manner allows to achieve parameters satisfactory to requirements for state of the art laser heterostructures with oversimplification all the fabrication processes. 